\title{
Experimental Study Of R141b Flow Boiling Compact Evaporator in Organic Rankine Cycle for Waste Heat Recovery
}

\author{
Candra Nurdiansyah ${ }^{1}$, Prabowo ${ }^{1}$, and Muhammad Yunus Abdullah ${ }^{1}$
}

\begin{abstract}
Indonesia is one of country that has plenty geothermal energy resource. Because of the significant potential, the energy can be used as a power plant. Geothermal resource with low pressure and temperature can be used in Organic Rankine Cycle (ORC) technology. ORC is one of power plant system which can use waste energy by using organic working fluid or refrigerant that is able to evaporate at low pressures and temperatures. In this research, experimental of evaporator by using the organic Rankine cycle system from the gas stove heat source.The experimental study was conducted by experimenting of evaporator Compact Heat Exchanger continuous fin type. For know typical of heat transfer, evaluation proses make three region, subcooled, evaporation and superhaet. The prediction of the Two phase change flow pattern was observed in detail against the effect of heat flux and mass velocity variations by Chen and Shah Correlation. The phase change process occurs under pressure conditions $P=5$ bar where the saturation temperature is 86.9 oCFrom the calculation and analysis, the maximum rate of heat transfer is $17.345 \mathrm{~kW}$ at $468 \mathrm{~kg} / \mathrm{m} 2 \mathrm{~s}$ and heat flux $83 \mathrm{~kW} / \mathrm{m} 2$. The evaporation process occurs at temperatures above 95 oC. Internal tube heat transfer coefficient of two-phase convection with consideration of the highest nucleate boiling and convective boiling of the evaporator was $2443.69 \mathrm{~W} / \mathrm{m} 2 \mathrm{~K}$ in $234 \mathrm{~kg} / \mathrm{m} 2 \mathrm{~s}$ mass flux refrigerant. Heat Flux with $1.94 \mathrm{~kW} / \mathrm{m} 2$ heaten (Chen's Methode) and from the result of analysis proposed by Shah's Methode was obtained $1624.90 \mathrm{~W} / \mathrm{m} 2 \mathrm{~K}$ in $468 \mathrm{~kg} / \mathrm{m} 2 \mathrm{~s}$ mass flux refrigerant and $1.94 \mathrm{~kW} / \mathrm{m} 2$ heat flux. the value of convection coefficient varies to the value of heat flux, mass flux and quality vapor.
\end{abstract}

Keywords-Organic Rankine Cycle (ORC), Waste Heat Recovery, Evaporator, Refrigerants, $\triangle T L M T D$, Heat Transfer Coeffcient, Saturation Temperature, Two-Phase.

\section{INTRODUCTION}

The utilization of low-grade heat sources including geothermal heat, biomass heat, solar power and industrial waste heat will greatly reduce the effect of the energy crisis. Among the various systems developed to use these lowtemperature heat sources, the Organic Rankine Cycle (ORC) has been shown to be a promising solution for generating power from several hundred kilowatts to several megawatts.

${ }^{1}$ Candra Nurdiansyah, Prabowo, and Muhammad Yunus Abdullah are with Department of Mechanical Engineering, Institut Teknologi Sepuluh Nopember, Surabaya, 60111, Indonesia. E-mail: candranurr@gmail.com; prabowo@me.its.ac.id; muhamadyunus13@gmail.com.
[1] Investigated flow boiling heat transfer with R-410A and carbon dioxide in a $6.1 \mathrm{~mm}$ inner diameter horizontal smooth tube. The heat transfer trends of carbon dioxide revealed the predominance of nucleate boiling, i.e. dependence upon the heat flux and independence upon the mass velocity and the vapor quality. Nucleate and convective boiling heat transfer mechanisms are active for R-410A flow boiling heat transfer (influence of heat flux, mass flux and quality). Performed experiments with R-113 during flow boiling through horizontal rectangular channels with low aspect ratios. The quality range was from 0.15 to 0.75 and the flow pattern appeared to be mainly annular. The heat transfer coefficients increased with the mass flux and the local quality, whereas the effect of the heat flux appeared to be minor. Convective boiling was therefore the dominant heat transfer regime.

The objective of this study is to provide experimental data for R141b flow boiling in horizontal tubes at low saturation pressures for ORC application, including the variation of heat transfer coefficient with vapor quality. The heat transfer characteristics were studied by analyzing the differences between chen correlation and shah correlation as well as the effects of the heat flux and mass flux on the heat transfer coefficient. This study aims to provide guidance for evaporator designs in ORC applications.

\section{EXPERIMENTAL METHOD}

Figure 1 shows a schematic of the major components in the experiment for two-phase flow boiling of organic fluids in organic rankine cycle systems at the various conditions listed. ORC system built using 4 main components namely turbine, condenser, pump, and evaporator. Evaporator and condenser used are compact heat exchanger type. The evaporator is immersed in thermal oil type thermo 32 and then heated by using 3 burners using LPG fuel. The system included the gear pump, condensation system and pressure control system (Pressure regulating Valve). ORC system initial planning is to determine heating and cooling fluid that is used. The principle of the evaporator is to absorb heat energy in the heated Heat transfer oil that is heated by gas stove where the pipe surface temperature assumed to be equal to temperature heat transfer oil.

\section{A. Experimental Apparatus}

First step for running prototipe, Evaporators and burners are placed outdoors so that the heat from the burner does 
not affect the condenser air cooler. The condenser is placed indoors and cooled by using air that flows using a blower. Condenser air cooler coming out of the condenser is drained out of the room by ducting. The velocity of condenser air cooler is varied by changing the frequency of the electric motor by using an inverter. The air velocity is measured on the sides before entering the condenser using an anemometer. The working fluid r141b is circulated by using gear pump and the working fluid flow rate is measured using the OMEGA flow meter type FLMW-240 BR. Sight glass is installed on the evaporator output to determine the working fluid phase conditions. Pressure gauges and $\mathrm{K}$ type thermocouples are installed on the main components for monitoring pressure and temperature. The temperature monitor is performed using the Yokogawa Data Acquisition type MX100 with measurement interval of $2 \mathrm{~s}$.

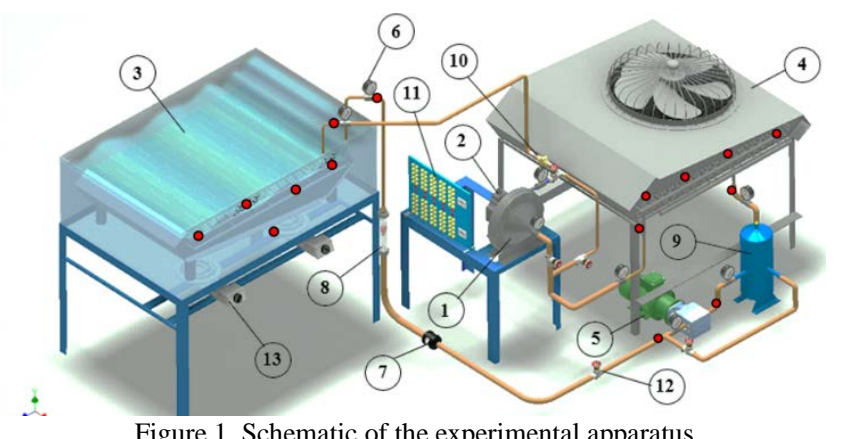

$\begin{array}{lll}\text { 1. } & \text { Turbin } & \text { 8. Flowmeter } \\ \text { 2. } & \text { Generator } & \text { 9. Receiver Tank } \\ \text { 3. } & \text { Evaporator } & \text { 10. Sight Glass } \\ \text { 4. } & \text { condensor } & \text { 11. Panel Lamp } \\ \text { 5. } & \text { Gear Pump } & \text { 12. Valve } \\ \text { 6. } & \text { Press. Gauge } & \text { 13. Burner } \\ \text { 7. } & \text { Filter Dryer } & \end{array}$

\section{RESULTS AND DISCUSSION}

Flow boiling models consider two heat transfer mechanisms to be important: nucleate boiling heat transfer and convective boiling heat transfer.These two main heat transfer mechanisms are combined to obtain the heat transfer coefficient.

\section{B. Effect of experimental parameters on heat transfer}

The more popular correlations incorporate both low quality and higher quality behavior in an additive fashion, the widely used Chen correlation, in which convective and nucleate boiling contributions are calculated separately and then added. The Chen Method was Originally devised for saturated boiling but can easily be extended to subcooled boiling by the superposition method

$$
h_{T P}=h_{c b}+h_{n b}=h_{L O} F+h_{p} S
$$

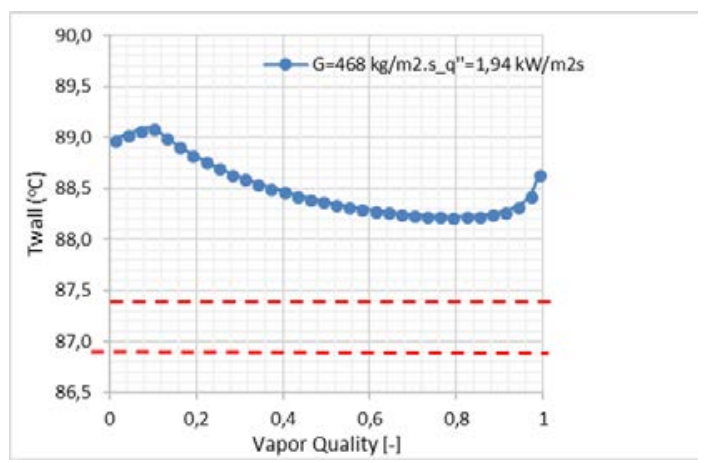

Figure 2. Temperatur wall Vs vapor quality

Because $T_{W}>T_{\text {WonB }}$ there is a nucleate boiling phenomenon and must be taken into account. Here is a graph of steam quality (0.01-0.99) against wall temperature. From the graph shows that the value of Twall above the value of saturation Temperature and the initial temperature of nucleate boiling $\left(\mathrm{T}_{\mathrm{WONB}}\right)$. so the calculation of two phases calculate the convective and nucleate boiling.

$$
\mathrm{T}_{\mathrm{w}}=\frac{\mathrm{q}^{\prime \prime}}{\mathrm{h}_{\mathrm{cb}}}+\mathrm{T}_{\mathrm{s}}
$$

C. Heat flux effect with convective dominant and both convective and nucleate dominant

When convective boiling is dominant, the heat transfer coefficient is independent of the heat flux and dependent on the mass flux and vapor quality.
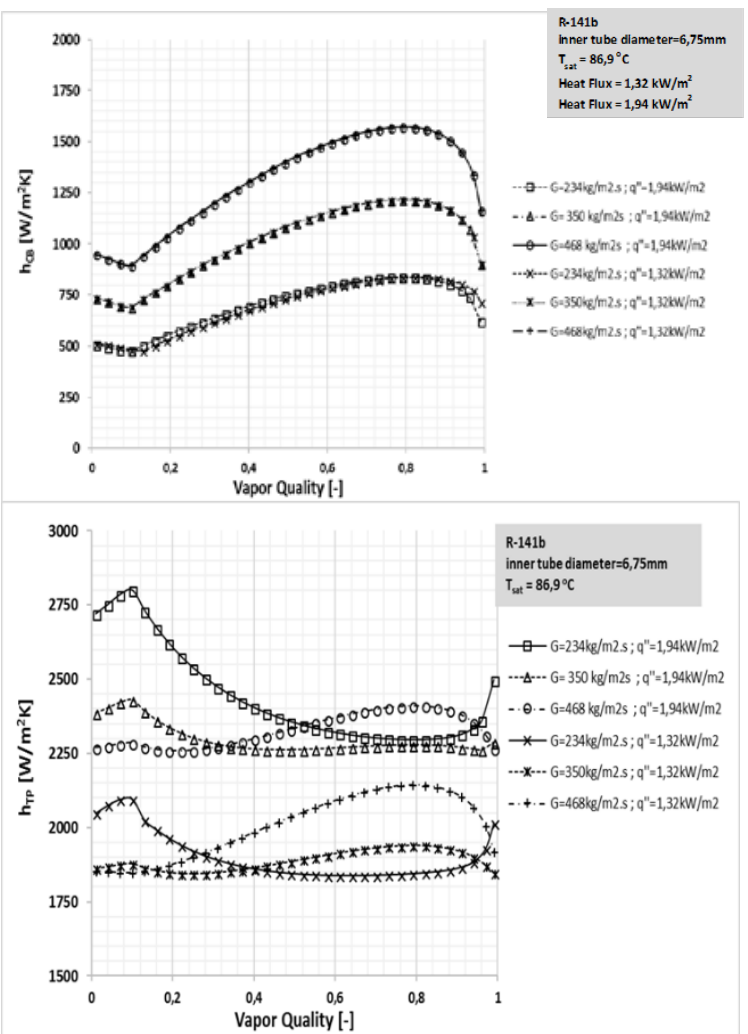

Figure 3. Convective boiling heat transfer coefficient dominant and both convective, nucleate heat transfer coefficient with variabel heat flux and mass velocity

Figure 3 get the graph of mass velocity and heat flux on the coefficient of two phase convection heat transfer. The 
chen correlation has a conventional two-phase Internal tube heat transfer coefficient with consideration of the highest nucleate boiling and convective boiling. the evaporator obtained at average coefficient convection heat transfer is $2443.69 \mathrm{~W} / \mathrm{m}^{2} \mathrm{~K}$ in a $234 \mathrm{~kg} / \mathrm{m}^{2} \mathrm{~s}$ mass flux refrigerant with $1.94 \mathrm{~kW} / \mathrm{m}^{2}$ heat flux. The lowest convective coefficient value of $1888.30 \mathrm{~W} / \mathrm{m}^{2} \mathrm{~K}$ there is a mass flux refrigerant of $350 \mathrm{~kg} / \mathrm{m}^{2} \mathrm{~s}$ with heat flux $1.32 \mathrm{~kW} / \mathrm{m}^{2}$. the value of convection coefficient varies to the value of heat flux, mass flux and vapor quality.

\section{Heat flux and Mass Velocity effect with nucleate} dominant

When nucleate boiling is dominant, the heat transfer coefficient is independent of the mass velocity and vapor quality, dependent on the heat flux and sensitive to the saturation pressure level. when both nucleate and convective boiling are of the same order of importance, the heat transfer coefficient is dependent on the heat flux, mass velocity and vapor quality.

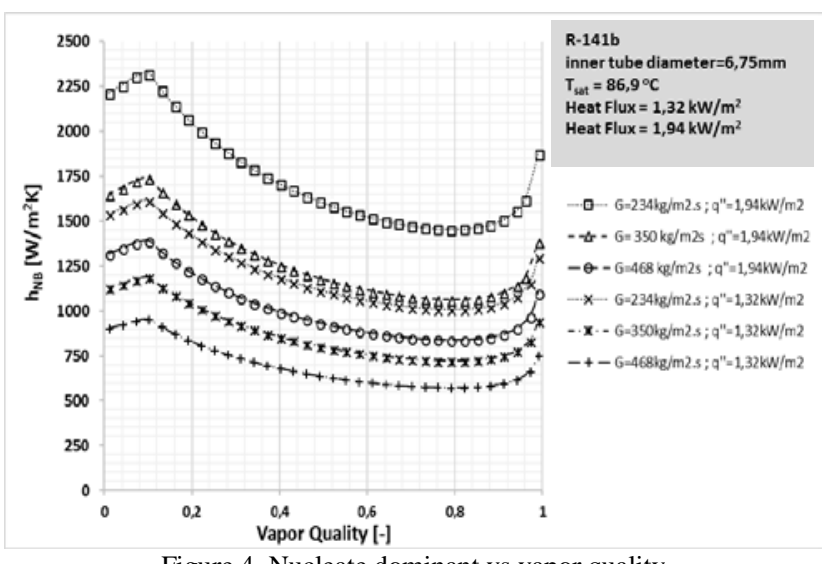

Figure 4. Nucleate dominant vs vapor quality

Nucleate boiling dominannt where with increasing vapor quality hence decreased velocity causing the value of $\mathrm{h}_{\mathrm{cb}}$ heat transfer coefficient also decrease and rise again at steam quality approaching 1 . It can be concluded that the value of nucleate heat transfer coefficient does not depend on mass velocity variation, but $h_{n b}$ value affect the value of the increase of oil temperature or heat flux and vapor quality. The average nucleate coefficient heattransfer value of the vapor quality of 0.01-0.99 obtained the largest value of $\mathrm{h}_{\mathrm{nb}}$ on heat flux $=1.92$ with a mass velocity of 234 $\mathrm{kg} / \mathrm{m}^{2}$.

\section{E. Immersed heat Exchanger}

To calculate the outer side convection coefficient depends on the properties of the fluid used and the average temperature of the oil when heated. The following calculations are presented in graphical form with two different approaches $\Delta \mathrm{T}_{\mathrm{LMTD}}$ method. At constant heating oil temperature, the value of convection coefficient tends to be constant with increasing mass flux of refrigerant in tube. $\Delta \mathrm{T}_{\text {LMTD }}$ is constant with increasing mass flux of refrigerant in the tube.

Farrington and Bingham correlation :

$$
\mathrm{Ra}_{\mathrm{D}}=\frac{\mathrm{g} \beta \mathrm{D}^{3}}{v \alpha} \mathrm{LMTD}_{\text {corr }}
$$

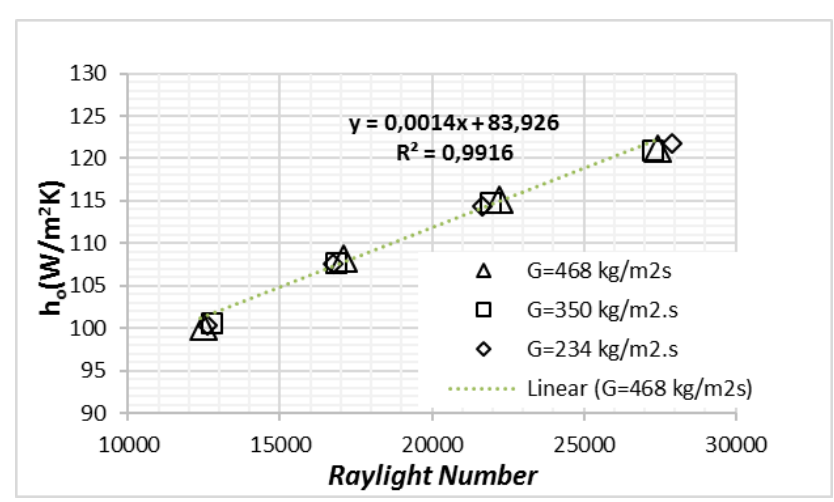

Figure 5. Raylight number vs coefficient conveksi heat transfer out side

In figure (a) indicates an increase in oil temperature also increases the convection coefficient value of the outer side of the tube. External side calculations take into account the tube and outlet tube temperatures and are calculated by (LMTD Method)

$$
L M T D=\frac{T_{C, \text { out }}-T_{C, \text { in }}}{\ln \left[\left(T_{C, \text { out }}-T_{\infty}\right) /\left(T_{C, \text { in }}-T_{\infty}\right)\right]}
$$

\section{F. Overall Heat Transfer Coefficient}

Figure 7 shows the relationship between the value of the Number of Transfer unit to the effectiveness of heat exchanger. Each line has a different $\mathrm{Cr}$ value, where $\mathrm{Cr}$ is the value of comparison between heat capacity and maximum heat capacity. Based on the theoretical formulation with increasing value NTU will be directly proportional to the increasing value.

Effectiveness $(\varepsilon)$ is the ratio of the heat exchanger heat transfer rate to the maximum allowable displacement rate. Effectiveness is a dimensionless number and is within the limit of $0<\varepsilon<1$. The data needed to determine the effectiveness of the evaporator is as follows

$$
\varepsilon=\frac{\mathrm{T}_{\mathrm{C}, \text { out }}-\mathrm{T}_{\mathrm{C}, \text { in }}}{\mathrm{T}_{\infty}-\mathrm{T}_{\mathrm{C}, \text { in }}}
$$

and

$$
\text { NTU }=- \text { LN }(1-\varepsilon)
$$

NTU method is a method used to determine the performance of the finished heat exchanger. With the test conditions ie the evaporator is not in the oil bath so no aa fluid flowing for the heating or external side of the evaporation process can be determined $\mathrm{Cr}=0$, 


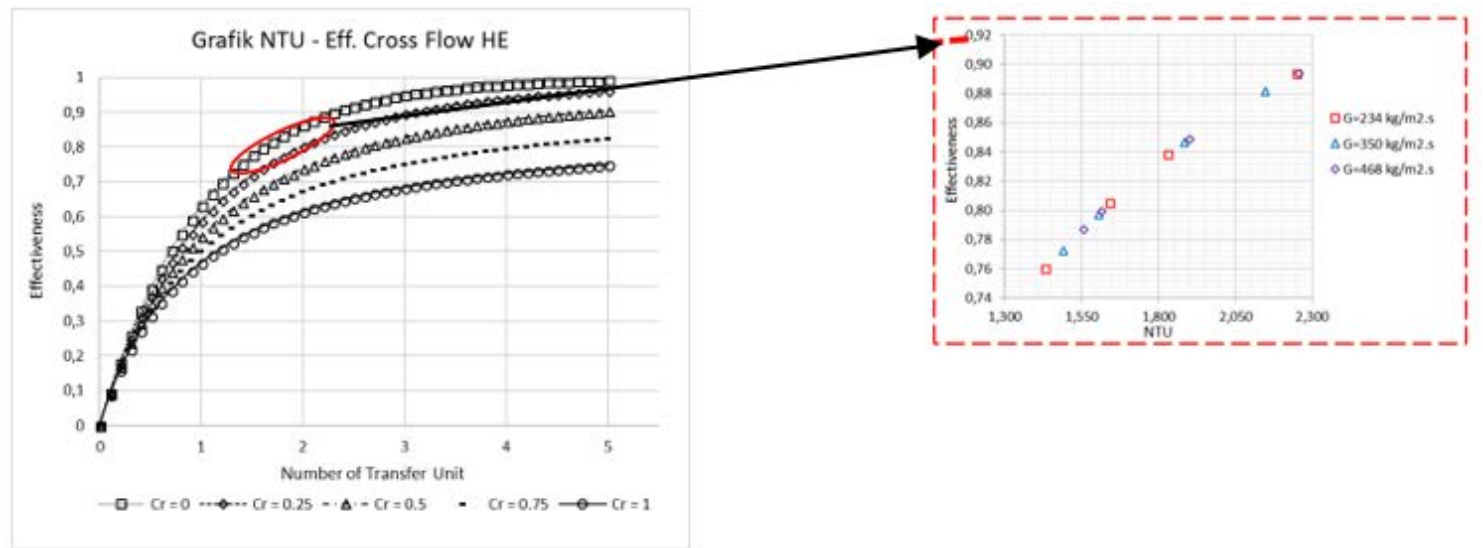

Figure 6. NTU Vs Effectiveness

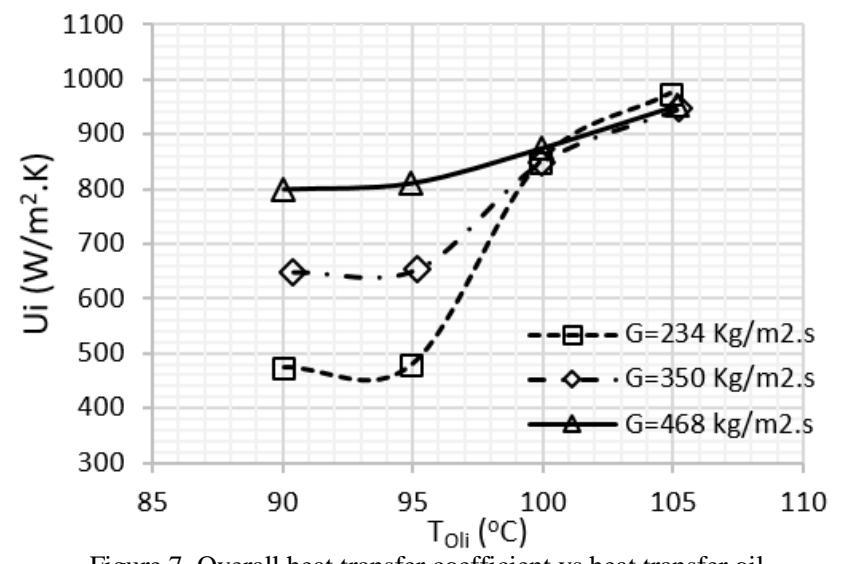

Figure 7. Overall heat transfer coefficient vs heat transfer oil

From the experimental results above shows that the value of Overall Heat Transfer Coefficient has a significant difference value to the increase in mass velocity. However, at the above $100^{\circ} \mathrm{C}$ and $105^{\circ} \mathrm{C}$ oil temperatures have a relatively equal Overall Heat Transfer Coefficient value of mass velocity variation. Increase the temperature value at the oil temperature above $100^{\circ} \mathrm{C}$ because the internal tube side condition undergoes phase-change process from liquid to steam and has Overall Heat Transfer Coefficient value which is dominated by nucleate and covective boiling process.

\section{CONCLUSIONS}

Horizontal flow boiling experiments were conducted with R141b at low saturation pressures required by Organic Rankine Cycles with analyses of the key parameters influencing the heat transfer characteristics, so that experimental data for evaporator design was provided. The heat transfer coefficients are then compared to existing correlations and an improved correlation is developed from the data.

The value of conventional average heat transfer coefficient convection by considering the area of each zone is $1911.87 \mathrm{~W} / \mathrm{m}^{2}$ in $468 \mathrm{~kg} / \mathrm{m}^{2} \mathrm{~s}$ mass flux refrigerant and heat flux $1.32 \mathrm{~kW} / \mathrm{m}^{2}$. While for heat flux $1,94 \mathrm{~kW} / \mathrm{m}^{2}$ got the biggest convection coefficient value $2300,37 \mathrm{~W} / \mathrm{m}^{2}$ that is at mass flux refrigeran $234 \mathrm{~kg} / \mathrm{m}^{2} \mathrm{~s}$. The largest Heat Transfer Coefficient is $46.89 \mathrm{~kW} / \mathrm{m}^{2}$ with $234 \mathrm{~kg} / \mathrm{m}^{2} \mathrm{~s}$ of mass flux refrigerant because Overall Heat Transfer Coefficient is more influenced by the internal tube heat transfer coefficient.

\section{REFERENCES}

[1] C. Y. Park and P. S. Hrnjak, "CO2 and R410A flow boiling heat transfer, pressure drop, and flow pattern at low temperatures in a horizontal smooth tube,” Int. J. Refrig., vol. 30, no. 1, pp. 166-178, Jan. 2007. 